Published in final edited form as:

Cognition. 2011 September ; 120(3): 322-330. doi:10.1016/j.cognition.2010.10.001.

\title{
The Double-edged Sword of Pedagogy: Instruction limits spontaneous exploration and discovery
}

\author{
Elizabeth Bonawitz ${ }^{1}$, Patrick Shafto ${ }^{2}$, Hyowon Gweon ${ }^{3}$, Noah D. Goodman ${ }^{4}$, Elizabeth \\ Spelke ${ }^{5}$, and Laura Schulz ${ }^{3}$ \\ ${ }^{1}$ Department of Psychology, University of California, Berkeley, Berkeley, CA 94720 USA \\ ${ }^{2}$ Department of Psychological and Brain Sciences, University of Louisville, Louisville, KY 40292 \\ USA \\ ${ }^{3}$ Department of Brain and Cognitive Sciences, Massachusetts Institute of Technology, Cambridge \\ MA 02139 USA \\ ${ }^{4}$ Department of Psychology, Stanford University, Stanford, CA 94305 USA \\ ${ }^{5}$ Department of Psychology, Harvard University, Cambridge MA 02138 USA
}

\begin{abstract}
Motivated by computational analyses, we look at how teaching affects exploration and discovery. In Experiment 1, we investigated children's exploratory play after an adult pedagogically demonstrated a function of a toy, after an interrupted pedagogical demonstration, after a naïve adult demonstrated the function, and at baseline. Preschoolers in the pedagogical condition focused almost exclusively on the target function; by contrast, children in the other conditions explored broadly. In Experiment 2, we show that children restrict their exploration both after direct instruction to themselves and after overhearing direct instruction given to another child; they do not show this constraint after observing direct instruction given to an adult or after observing a non-pedagogical intentional action. We discuss these findings as the result of rational inductive biases. In pedagogical contexts, a teacher's failure to provide evidence for additional functions provides evidence for their absence; such contexts generalize from child to child (because children are likely to have comparable states of knowledge) but not from adult to child. Thus, pedagogy promotes efficient learning but at a cost: children are less likely to perform potentially irrelevant actions but also less likely to discover novel information.
\end{abstract}

\section{Key Terms}

Pedagogy; Bayesian Model; Exploratory Play; Discovery; Causal Learning; Cognitive Development

\section{(C) 2010 Published by Elsevier B.V.}

Correspondence to: Elizabeth Bonawitz.

The first two authors contributed equally to this work.

5 After the demonstration in the Indirect Child Conditions, a research assistant helping the experimenter gave the child who was recruited as the target of instruction another activity to pursue, out of sight of the child who was the experimental participant. Parents who participated in the Indirect Adult Conditions stepped out of their child's line of sight.

Publisher's Disclaimer: This is a PDF file of an unedited manuscript that has been accepted for publication. As a service to our customers we are providing this early version of the manuscript. The manuscript will undergo copyediting, typesetting, and review of the resulting proof before it is published in its final citable form. Please note that during the production process errors may be discovered which could affect the content, and all legal disclaimers that apply to the journal pertain. 
The principal goal of education is to create men who are capable of doing new things, not simply of repeating what other generations have done - men who are creative, inventive and discoverers.

Jean Piaget.

Two competing intuitions animate longstanding debates over children's learning: that children learn primarily from helpful, informative others (through testimony or "direct instruction"; Vygotsky, 1978; Csibra \& Gergeley, 2009; Gergely, Kiraly, \& Egyed, 2007; Koenig \& Harris, 2005; Kushnir, Wellman, \& Gelman, 2008; Tomasello \& Barton, 1994), and that, especially in the early years, children learn chiefly through their own active exploration of the environment ("constructivist" or "discovery learning"; Bonawitz, Lim, \& Schulz, 2007; Bonawitz \& Schulz, in review; Bruner, Jolly, \& Sylva, 1976; Gweon \& Schulz, 2008; Piaget, 1929; Schulz \& Bonawitz, 2007; Singer, Golinkoff, \& Hirsh-Pasek, 2008). Here we suggest that the tension between learning from others and from self-guided exploration stems in part from a principled trade-off at the heart of pedagogical learning. Teaching ${ }^{1}$ produces an inductive bias that constrains children's hypothesis space for better and for worse: in promoting rapid and efficient learning of target material, pedagogical instruction necessarily limits the range of hypotheses children consider.

Our inquiry is motivated by an ideal learner analysis-what should a student infer from evidence given by a helpful teacher? Recent research has formalized pedagogical learning as an inference based on the paired assumptions that a learner will rationally update her belief in a hypothesis given new data (from a pedagogical demonstration) and that a teacher will choose data (a particular demonstration) likely to increase the learner's belief in the correct hypothesis (Shafto \& Goodman, 2008; Shafto, Goodman, \& Griffiths, in review). In what follows, we present details of our Bayesian analysis and two experiments motivated from this analysis, exploring the consequences of pedagogical inference on preschool-aged children's exploration and discovery.

An ideal learner will update her beliefs rationally given the demonstration (or data), $d$, as described by Bayes' theorem:

$$
P_{L}(h \mid d) P(d \mid h) P_{L}(h) .
$$

In Equation 1, $P_{L}(h)$ represents the learner's prior beliefs in a hypothesis $h$. The term $P(d / h)$, called the likelihood or sampling assumption, captures the learner's assumption about the source of the data. If the learner did not believe the data were chosen by a helpful teacher, then we would use a default sampling assumption in equation (1): $P_{D}(d / h)$. This default will depend on the situation, and captures the natural source of evidence in the absence of a teacher (e.g. by random exploration). However, if the learner assumes that a helpful teacher has chosen the data, we must use a pedagogical sampling assumption:

$$
\begin{gathered}
P_{L}(h \mid d) P_{T}(d \mid h) P_{L}(h), \\
P_{T}(d \mid h) P_{T}(h \mid d)
\end{gathered}
$$

Equation 2 captures the idea that the data are chosen by the teacher in such a way that they will increase the probability that the learner assigns to the correct hypothesis. Note that the

\footnotetext{
${ }^{1}$ Throughout, reference to teachers and teaching refer, not only to classroom instruction, but to any knowledgeable, helpful communicative partner providing instruction to a less knowledgeable partner.
} 
teacher's choice of data depends in turn on the assumption that the learner will rationally update her beliefs. Equations 1' and 2, and the default sampling assumption, define a system of equations that provides a model of how having a teacher should affect a learner's inferences. Intuitively, one can imagine beginning with the inferences the learner would draw under the default sampling assumption, then using equations 1' and 2 iteratively to "strengthen" these inferences into the ideal pedagogical inferences. (See Shafto \& Goodman, 2008; Shafto, Goodman, \& Griffiths, under review, for further discussion.)

Consider, for example, inferences about novel toy, which has $M$ potential affordances (a fixed, but arbitrary, large number) of which an unknown number, $n$, will activate latent functions. We imagine a default sampling process in which $m$ affordances are tested at random (without knowledge of which ones have a function-this is called a weak sampling assumption, Tenenbaum, 1999). Under this default, an observation of $m$ tests resulting in $n$ functions provides strong evidence for these $n$ functions but provides no evidence for, or against, any functions of untested affordances. In particular, the learner gains no information beyond her a priori beliefs about the untested affordances: even though she may believe that functions are rare (Oaksford \& Chater, 1994) and hence additional functions are unlikely, the evidence does not enhance this inference compared to baseline.

In a pedagogical context, by Equation 2, a teacher should demonstrate all the actual functions: if she demonstrated fewer, the learner would consider more hypotheses, and hence, each (including the correct one) would receive lower probability. She should demonstrate the functioning affordances (rather than the non-functions) because these are $a$ priori rare; hence, observing them raises the probability of the correct hypothesis more than observing non-functions. Given this, the learner will infer, by Equation 1', that the demonstrated functions are exhaustive - all the functions will be demonstrated by a helpful teacher. (Further iterations of Equations 1' and 2 will strengthen this inference, but not change the qualitative conclusion.) Thus, the inference that there are no additional functions to be discovered will be strong in a pedagogical context but weak (and no stronger than at baseline) in a default context.

What factors affect whether a child should interpret a given context as pedagogical? The above analysis depends on the assumption that the data are chosen by a knowledgeable, helpful teacher. If the evidence is sampled randomly (e.g., by a teacher who is ignorant of the true hypothesis or by the naïve learner herself), the default sampling assumption should be used, as described above, and the absence of additional functions should not be inferred. Similarly, if the teacher is interrupted in the middle of giving the evidence, it will be ambiguous whether the teacher would have gone on to demonstrate additional functions; in this case the evidence also does not imply absence of additional functions. Note that we will treat such cases as "non-pedagogical", even if they involve superficial cues to pedagogy (i.e., an adult engaging in joint attention and providing ostensive communicative cues to a child; Csibra \& Gergely, 2009). Such cues may be useful precisely because they tend to predict pedagogical sampling, but if, in a particular instance, pedagogical sampling has clearly not occurred, the inferential assumptions of pedagogy should not hold.

This analysis suggests a trade-off between instruction and exploration. Because pedagogical inferences constrain the hypotheses children consider, children should be efficient learners in pedagogical contexts, but they may well assume there is nothing further to learn. (If there were, the teacher should have provided evidence accordingly.) Thus, when a knowledgeable teacher freely demonstrates a function of a toy, children should engage in relatively limited exploration and discover little else about the toy. By contrast, in non-pedagogical contexts, children should not be restricted to any one function, even if demonstrated. Children should take all the toy's affordances into account (as they would at baseline) and thus explore 
broadly. In Experiment 1, we test these predictions by looking at whether, relative to children in non-pedagogical contexts, children given pedagogically sampled evidence about a toy explore the toy more briefly, perform fewer unique actions, and discover fewer nondemonstrated functions.

\section{Experiment 1}

\section{Methods}

Participants-Eighty-five preschoolers participated (mean age: 58 months; range: 48-72 months) in an urban science museum. Most children were white and middle-class, but a range of ethnicities resembling the diversity of the population was represented.

Design-Preschoolers participated in one of four conditions: 25 children in a Pedagogical condition and 20 each in one of three Non-Pedagogical conditions: Interrupted, Naive, and Baseline. There were no differences in the age of the children across conditions: $\mathrm{F}(4,81)=0.30, p=n s$.

Materials-A novel-looking toy was created using colored PVC pipes attached to a board (see Figure 1). The toy was approximately $18^{\prime \prime} \times 6^{\prime \prime} \times 15^{\prime \prime}$. The toy had four different nonobvious causal affordances: it made a squeak sound when a yellow-colored tube was pulled out from inside a larger purple tube; one end of a blue tube lit up when a small button hidden inside the other end was pressed; a small yellow pad attached to the plastic board played music notes when different parts of the pad were pressed; there were two adjoining black tubes with mirrors inside so that a reversed mirror image of the observer's face was visible. All other aspects of the toy were inert.

Procedure-Children were tested individually in a quiet corner of the museum. In all conditions, the experimenter brought the toy out from under the table. In the Pedagogical condition, the experimenter said, "Look at my toy! This is my toy. I'm going to show you how my toy works. Watch this!" The experimenter then pulled the yellow tube out from the purple tube to produce the squeak sound. She said, "Wow, see that? This is how my toy works!" and demonstrated the same action again. The Interrupted condition was exactly like the Pedagogical condition, except that the experimenter interrupted herself immediately after the demonstration saying, "I just realized, I have to stop because I forgot to write down something over there. I have to go take care of it right now!'” In the Naïve condition, the experimenter said, "I just found this toy! See this toy?" As she brought out the toy from underneath the table, she pulled the yellow tube out from the purple tube as if she did so by accident. Then she said as if surprised, "Huh! Did you see that? Let me try to do that!" and performed the same action to produce the squeak sound. In the Baseline condition, the experimenter did not initially demonstrate the squeaking function of the toy. After she brought out the toy from underneath the table, she picked up the toy and said, "Wow, see this toy? Look at this!" She looked at the toy for about 2 seconds (to match the other conditions for amount of familiarization time), and then put it back on the table.

In all conditions, the experimenter then said, "Wow, isn't that cool? I'm going to let you play and see if you can figure out how this toy works. Let me know when you're done!" and left the child to play. If the child said that she was finished or stopped interacting with the toy for more than 5 consecutive seconds without indicating completion, the experimenter prompted the child by saying, "Are you done?" She returned to the table and terminated the experiment if the child answered, "Yes". Otherwise, she let the child continue to play and then returned to the table to terminate the experiment if the child stopped interacting with the toy a second time for more than 5 seconds. All sessions were videotaped and coded by a 
research assistant blind to hypothesis and a second research assistant blind to hypotheses and condition. Total playtime, the number of unique actions performed, time playing with the squeaker, and the number of target functions (light, music, and mirror) discovered during play were coded. All but two children (excluded due to technical malfunction) were reliability coded on total playtime, unique actions, and number of target functions; $75 \%$ of clips were reliability coded for time with squeaker.

\section{Results and Discussion}

Because we had a priori hypotheses about the patterns of results, we performed planned linear contrasts throughout. We formalized the prediction that the Pedagogical condition would differ from the Interrupted, Naïve and Baseline conditions and that the NonPedagogical conditions would not differ from each other by conducting the analyses with the weights $3,-1,-1$, and -1 for the four conditions, respectively. The analyses will thus be significant when there is a difference between the Pedagogical and Non-Pedagogical conditions, and no difference among the Non-Pedagogical conditions.

To look at whether children engaged in less exploration in the Pedagogical condition than in the other three conditions, we coded children's total time playing, the number of unique actions children performed, the proportion of children's play time spent only on the demonstrated function (excluding the Baseline condition where no demonstration was provided), and the total number of target functions discovered in the course of free play. For the number of unique actions performed, we coded all the actions children performed during free play, which included all four possible target actions in addition to any other kind of action the child performed; we enumerated the different kinds of actions, rather than individual actions per se. (Thus, seven pulls on the tube were counted as one action, whereas one pull on the tube and one activation of the light were counted as two actions.) Reliability on all measures was high. (Total time playing: $\mathrm{r}^{2}=.99$; Actions taken on toy: kappa=.77; Time playing with squeaking tube: $\mathrm{r}^{2}=.96$; Functions discovered: kappa $=.86$ ).

All the linear contrasts were significant. Children in the Pedagogical condition played with the toy for significantly less time ( $\mathrm{M}=119.2 \mathrm{~s})$ than children in the Interrupted $(\mathrm{M}=179.6 \mathrm{~s})$, Naïve $(\mathrm{M}=132.7 \mathrm{~s})$, or Baseline $(\mathrm{M}=205.7)$ conditions $(\mathrm{F}(1,81)=4.52, \mathrm{p}<0.05)$. Children in the Pedagogical condition also performed fewer different kinds of actions on the toy $(\mathrm{M}=4.00)$ than children in the Interrupted $(\mathrm{M}=5.30)$, Naïve $(\mathrm{M}=5.90)$ or Baseline $(\mathrm{M}=6.15)$ conditions, $\mathrm{F}(1,81)=9.39, \mathrm{p}<0.01)$. This result held even when the playtime was matched across conditions; looking only at the number of actions performed in the first 60 seconds, children in the Pedagogical condition performed fewer actions $(\mathrm{M}=3.16)$ than children in the Interrupted $(\mathrm{M}=3.75)$, Naïve $(\mathrm{M}=4.90)$, and Baseline $(\mathrm{M}=4.15)$ conditions, $F(1,81)=7.18, p$ $<0.05$.

What did children do when they played? Although children in the Pedagogical, Interrupted, and Naïve condition had all seen the experimenter pull the tube to make the squeak sound, they did not spend equal proportions of their playtime acting on the squeaker tube across conditions. Children in the Pedagogical condition spent a greater proportion of time playing with the squeaker $(\mathrm{M}=0.68)$ than children in the other conditions where the squeaker was demonstrated: Interrupted $(\mathrm{M}=.53)$, Naive $\left(\mathrm{M}=.38\right.$ ) conditions, $\mathrm{F}(1,62)=13.91, \mathrm{p}<0.001 .^{2}$ Finally, we gave children one point for each of the target functions, other than the squeaker tube, that they discovered during their free play. Thus, children could receive a score between 0 and 3. Children in the Pedagogical condition discovered fewer of these target

\footnotetext{
${ }^{2}$ Because the Baseline condition was not included in this analysis, the linear contrast weight were adjusted to $2,-1,-1$.
} 
functions ( $\mathrm{M}=0.72)$ than children in the Interrupted $(\mathrm{M}=1.3)$, Naïve $(\mathrm{M}=1.2)$, or Baseline $(\mathrm{M}=1.15)$ conditions, $\mathrm{F}(1,81)=4.58, \mathrm{p}<0.05$.

These results suggest that teaching constrains children's exploration and discovery. Children who were taught a function of a toy performed fewer kinds of actions of the toy and discovered fewer of its other functions, than children who did not receive a pedagogical demonstration, even though all children were explicitly encouraged to explore the toy. We predicted such constrained exploration as the result of a rational inductive inference: if a knowledgeable teacher provides evidence for a function of a toy, absence of evidence for alternative functions provides strong evidence for their absence.

\section{Experiment 2}

Our ideal learner analysis suggests that the assumptions of pedagogical sampling apply when the learner believes that the teacher is choosing evidence in order to convey a particular hypothesis. As discussed, this implies that learners might treat some contexts as "non-pedagogical" even though an adult engages in direct, ostensive cuing to a child (as in the Naïve and Interrupted conditions of Experiment 1). Critically, the converse is also true: children might treat some contexts as "pedagogical" even in the absence of direct, ostensive cueing. According to the model, the teacher should choose data that are tailored to the individual being taught. Thus, the pedagogical model can apply both to situations when the teacher is directly teaching the learner, and to situations when the learner overhears a teacher instructing someone else whose prior beliefs are similar to the learner's own. This predicts that learners may engage in pedagogical inference even when merely observing, rather than participating in, a pedagogical situation. We call the requirement needed to engage pedagogical assumptions for overheard teaching the "similar priors" assumption.

Formally, the teacher's choice of data, $P_{T}(d / h)$, should depend on the learner's prior beliefs, $P_{L}(h)$, as described by Equations 1' and 2. In the basic pedagogical situation, there is a teacher and a learner (L1). Now consider a situation in which there is a second learner, L2, who has the same prior beliefs as L1 and vicariously observes the interaction between the teacher and L1. In this case, the data generated by the teacher are intended to teach L1; however, because L2 has the same prior beliefs as L1, Equations 1' and 2 are identical to what they would be if the teacher would had intended to teach L2. Consequently, if L2 is observing while L1 is being taught, and L2 can assume that she and L1 have similar beliefs, then $\mathrm{L} 2$ can treat a pedagogical demonstration to $\mathrm{L} 1$ as if it were a demonstration to $\mathrm{L} 2$ herself. In contrast, if the priors for the learners are very different $\left(P_{L I}(h) \neq P_{L 2}(h)\right)$, then appropriate demonstrations could be quite different for the different learners-a teacher would potentially choose different data to teach the same hypothesis to the different learners ${ }^{3}$. Thus, if $\mathrm{L} 2$ is observing $\mathrm{L} 1$ and assumes that $\mathrm{L} 1$ has beliefs different from her own, then she should not assume that the pedagogical demonstration to L1 generalize to herself.

Most previous research (e.g. Gergely, Bekkering, \& Kiraly, 2002; Topal et al., 2008; see Csibra \& Gergely, 2009 for a review) has focused on one-on-one pedagogical situations in which the teacher engages the learner using direct ostensive cuing (e.g., establishing eyecontact, shifting gaze between the object and the learner, and using the child's name) prior to the demonstration. Such work suggests that children are more likely both to learn demonstrated material and to generalize it to novel contexts in teaching than in non-teaching situations (e.g. Gergely, Bekkering, \& Kiraly, 2002; Topal et al., 2008; see Csibra \&

${ }^{3}$ This assumption also holds if L2 believes that L1's interests were different (e.g. the teacher may not demonstrate all the functions to $\mathrm{L} 1$ because she assumed that some of the functions would not be interesting to L1, but those functions may be interesting to L2.) 
Gergely, 2009 for a review). This is consistent with Csibra and Gergely's (2009) proposal that ostensive cuing engages special learning mechanisms (see also Tomasello et al., 2005). Under these theories, ostensive cues are a critical component of pedagogy; we might therefore expect that the effects of teaching would only be present when ostensive cues are directed towards the learner herself.

However, our analysis suggests a more nuanced relationship between indirect cues in pedagogy and the resulting inferences of the observing learner. In an indirect pedagogical demonstration, a knowledgeable teacher engages a child (L1) in ostensive cuing and then demonstrates a function of the novel toy with a second learner (L2) observing. The teacher's choice of demonstrations depends only on the learner's (L1's) beliefs. Thus, the overheard demonstration supports the same inferences as a direct pedagogical situation if the observer (L2) believes that the learner's (L1's) beliefs are like her own. The observer should not draw inferences consistent with pedagogical sampling if the demonstration is to a learner with different beliefs than the observer's own.

In Experiment 2, we look at whether children's pedagogical inferences depend primarily on direct ostensive cueing or whether pedagogical inferences are also engaged when an observing child shares knowledge states with the recipient of direct instruction. To investigate children's inferences in indirect pedagogical situations, we contrast exploratory play in four conditions: after a direct pedagogical demonstration (the Direct condition), after an indirect demonstration to a child (the Indirect Child condition), after an indirect demonstration to an adult (the Indirect Adult condition), and after a non-pedagogical intentional action that the child overhears (the Intentional condition). The Direct condition provides a replication of the Pedagogical condition in Experiment 1: children should show limited exploration and be less likely to discover the other, non-demonstrated properties of the toy. The Intentional condition, provides a control for the intentional manipulation of the toy, but does not provide pedagogical information for the children (see also Goodman, Baker, Tenenbaum, 2009). In this condition, the experimenter performs the same action as in the pedagogical condition, but makes it clear to the child that her intention is to satisfy her own preferences not to engage in instruction. We expect that children will explore readily in this condition, replicating the Baseline and Accidental conditions of Experiment 1.

Our key questions center on the Indirect Child and Indirect Adult conditions. If pedagogical inferences depend on direct ostensive cuing, then children in both of the Indirect conditions should be less susceptible to the pedagogical context, thus exploring the toy more and discovering more of its properties, than children in the Direct condition. If direct ostensive cues are not necessary, and pedagogical inferences extend to situations where the observing and observed learner have similar beliefs, then we expect a different pattern of results. Namely, we predicted that children would treat another child as having beliefs similar to their own but would not make this assumption about adult learners. If this is the case, then children should extend the pedagogical inference in the Indirect Child condition but not in the Indirect Adult condition. As a result, we predict more exploratory play and discovery learning in Indirect Adult condition than in the Indirect Child condition.

\section{Methods}

Participants-Sixty-four ${ }^{4}$ preschoolers (mean age: 61 months, range: $48-72$ months; 56\% girls) were recruited in a metropolitan Science Museum. Most children were white and

\footnotetext{
${ }^{4}$ Two children were dropped and replaced. One child was replaced because of a technical error (camera malfunctioned; play was not coded; Indirect Adult condition), and the second child fell off her chair during the experiment and could not continue (Indirect Child condition).
} 
middle-class, but a range of ethnicities resembling the diversity of the population was represented.

Design-Preschoolers were randomly assigned to one of four conditions: Direct, Indirect Child, Indirect Adult, or Intentional condition. There were no differences in the age of the children across conditions: $\mathrm{F}(2,56)=0.58, p=n s$. An additional sixteen children (unrelated to the participants and approximately the same age) were recruited as the primary learners in the Indirect Child condition and sixteen adults (parents of the children) participated as primary learners in the Indirect Adult condition.

Materials-The same novel toy from Experiment 1 was used.

Procedure-Children were tested in a quiet corner in the museum. The experiment included two phases: observation and play.

Observation phase: In the observation phase, children observed a demonstration of one property of the toy, which varied by condition. As in Experiment 1, in the Direct condition, the experimenter said, "Look at my toy! This is my toy. I'm going to show you how my toy works. Watch this!" The experimenter then pulled the yellow tube out from the purple tube to produce the squeak sound. She said, "Wow, see that? This is how my toy works!" and demonstrated the same action again. In the Indirect Child, and Indirect Adult conditions, the experimenter first said to the child participant "I have to go over here for a second, but I'll be right back." The experimenter then moved to a table approximately 2 meters from the participant and performed the procedure above either to the other child recruited for this purpose (Indirect Child) or to the observing child's parent (Indirect Adult). In the Intentional condition, the demonstrator said to the child, "Look at my toy. This is my toy. I have to go over here for a second, but I'll be right back." As with the Indirect conditions, the experimenter moved approximately 2 meters from the child participant but then said (talking out loud, to herself) "I like to make my toy squeak. Wow! I'm going to do that again" and performed the action twice without any ostensive cuing.

Play phase: After the child observed that pulling the tube made the squeaking sound, the experimenter (returning to the table in the Indirect5 and Intentional conditions) said, "I'm going to go ahead and let you play. Let me know when you're done!" and left the child to play. Play was ended following the same criteria as Experiment 1.

\section{Results and Discussion}

The results were analyzed as in Experiment 1. We formalized the prediction that the Direct and Indirect Child conditions would differ from the Indirect Adult and Intentional conditions using contrast weights of 1,1 , and $-1,-1$, respectively. The analyses will be significant when there is a difference between mean of the Direct and Indirect Child and the mean of the Indirect Adult and Intentional conditions, and no differences between the Direct and Indirect Child conditions, and the Indirect Adult and Intentional conditions.

As in Experiment 1, we coded children's total time playing, the number of different kinds of actions the children performed, their time spent on only the demonstrated function (the squeaking tube), and the number of target functions discovered in the course of free play. All children were reliability coded on action and play measures. Reliability coders were blind to condition and hypotheses. Reliability on all measures was high. (Actions taken on toy: kappa=0.82; Total time playing: $r=0.99$; Time playing with squeaking tube: $r=0.96$ ). 
With the exception of overall play time, which did not differ between conditions (Direct, $\mathrm{M}=70 \mathrm{~s}$; Indirect Child $\mathrm{M}=105 \mathrm{~s}$, Indirect Adult $\mathrm{M}=84 \mathrm{~s}$, Intentional, $\mathrm{M}=125 \mathrm{~s} ; F(1,60)=.92$, $p=n s)$ all the linear contrasts were significant. Children in the Direct $(\mathrm{M}=3.13)$ and Indirect Child $(\mathrm{M}=3.94)$ condition performed fewer different kinds of actions on the toy than children in the Indirect Adult ( $\mathrm{M}=5.31)$ and Intentional $(\mathrm{M}=5.13)$ conditions, $F(1,60)=11.50$, $p<0.01$. The difference between the $\operatorname{Direct}(\mathrm{M}=2.88)$ and Indirect Child $(\mathrm{M}=2.94)$ and Indirect Adult $(\mathrm{M}=4.94)$ and Intentional $(\mathrm{M}=4.38)$ conditions persists considering only actions produced in the first 60 seconds of play, $F(1,60)=17.57, p<.0001$.

What did children do when they played? Although children had all seen the experimenter pull the tube to make the squeak sound, children in the Direct $(\mathrm{M}=52 \%)$ and Indirect Child $(\mathrm{M}=60 \%)$ conditions spent a larger percentage of their playtime acting on the squeaking tube than children in the Indirect Adult ( $\mathrm{M}=37 \%)$ and Intentional ( $\mathrm{M}=36 \%)$ conditions, $F(1,60)=10.08, p<.01$. Looking at individual children, we gave children one point for each of the non-demonstrated functions that they discovered, thus children could receive a score between 0 and 3. Children's mean score was lower in the Direct $(\mathrm{M}=.50)$ and Indirect Child $(\mathrm{M}=.75)$ conditions than the Indirect Adult $(\mathrm{M}=1.31)$ and Intentional $(\mathrm{M}=1.00)$ conditions, $F(1,60)=6.38, p<.05$, even when controlling for duration of play by considering only the first 60 seconds (Direct, $\mathrm{M}=.44$; Indirect Child, $\mathrm{M}=.44$; Indirect Adult, $\mathrm{M}=1.19$; Intentional, $\mathrm{M}=$. $81 ; F(1,60)=9.88, p<0.01)$.

These results replicate and extend the findings of Experiment 1, showing that preschoolers' tendency to explore and discover new properties are limited in pedagogical settings relative to other intentional conditions. Moreover, they show that preschool children rationally extend their assumptions about pedagogical situations to contexts in which they overhear instruction to comparable learners; they are not dependent on direct ostensive cues. Note that it is possible that children were less likely to constrain their exploration in the Indirect Adult than the Indirect Child condition simply because they paid less attention to the former than then latter. Certainly children might have found an unfamiliar child more interesting than the familiar parent. We cannot rule this explanation out entirely. However, one reason to believe it is not the case, is that the conditions differed only with respect to children's tendency to infer the absence of uninstructed functions; children were equally likely to learn the demonstrated function in the two conditions. Of course, we do not know exactly in what respects children believed that their own knowledge was comparable to another child's but not to an adult's; they might for instance have assumed that relative to other children, adults are either more or less knowledgeable about toys. Future research might investigate in more detail what aspects of knowledge go into how children infer "similar priors" between themselves and another learner. However, the current results suggest that even very young children consider the prior knowledge of other learners in identifying contexts that license the inferences of pedagogical sampling.

\section{General Discussion}

Inspired by the ideas of Piaget and Vygotsky, we set out to investigate the implications of explicit instruction on exploratory play. We presented a formal model that captures our intuitions about how sampling assumptions (in pedagogical and non-pedagogical contexts) could influence a learner's hypothesis space about possible causal models of the world. Our empirical results are consistent with the qualitative predictions of our model. The results suggest that teaching constrains children's exploration and discovery. Children who were taught a function of a toy performed fewer kinds of actions on the toy and discovered fewer of its other functions, than children who did not receive a pedagogical demonstration. We predicted such constrained exploration as the result of a rational inductive inference: if a 
knowledgeable teacher provides evidence for a function of a toy, absence of evidence for alternative functions provides strong evidence for their absence.

The children's behavior is rational but is it desirable? If showing four and five-year-olds a function of a toy means that they explore less and consequently learn less about it, do the costs of direct instruction outweigh the benefits? We believe that there is no fully general answer to this question. The costs and benefits of instruction depend on how knowledgeable and helpful the teacher is, and on how likely the learner is to discover either the target information or novel information on her own. The inductive bias by which teaching constrains the learner's hypothesis space cuts both ways.

These trade-offs can be seen in our example. In order to investigate the effect of instruction on exploration, we deliberately designed a toy with more affordances than we demonstrated. A knowledgeable teacher, with sufficient time and motivation and without other constraints, would have shown the children all the target functions. In this case, not only would the children have learned all four functions, there would also arguably have been little else for them to discover. Given such a teacher, increasing the probability that children will learn the target information may be well worth decreasing the (already low) probability that they will discover novel information. By contrast, a teacher who knows only one of our toy's functions or who is constrained in her actions might be able to demonstrate only a single function (as the experimenter, deceptively, did here). Such instruction effectively focused children on the target function, but impaired their ability to discover novel information. Thus, if a teacher is relatively uninformed and/or a domain is largely unexplored, there may be advantages to seeing what the learner does spontaneously. Even as simple a recourse as delaying instruction until the learner has had a chance to investigate on her own could promote innovation and discovery. Critically however, even a knowledgeable teacher (e.g., one who knows all four functions of our toy), cannot know what currently unknown information might be discovered by the variable actions children perform in the absence of instruction. Because the total amount of information that might be learned is neither fixed nor known, the inductive trade-off introduced by pedagogy is a general one.

Our results also suggest that direct, ostensive cues are neither sufficient nor necessary for children to treat a demonstration as pedagogical. In cases where children were given direct, ostensive cues but there was reason to believe that the adult was not sampling evidence in proportion to the probability that it would generate the target hypothesis in the learner (e.g., because the teacher was interrupted or naïve), children did not draw the strong inferences licensed by pedagogical sampling (Experiment 1). Conversely, in cases where children lacked direct, ostensive cueing but a helpful teacher was instructing a learner with knowledge comparable to the child's own, children did assume pedagogical sampling (Experiment 2). Importantly, however, ostensive cues (even when directed to other learners) were not in themselves sufficient for children to engage pedagogical sampling assumptions. Consistent with our analysis, children suspended these assumptions when the target of the ostensive cueing was an adult learner whose beliefs were likely to differ from their own.

Our results support the predictions of our Bayesian model of pedagogy; however, they are not inconsistent with the proposals of Csibra, Gergely, and colleagues. We agree with other researchers (Csibra \& Gergely, 2009; Tomasello et al., 2005) that direct ostensive cues are probabilistically associated with pedagogical contexts, and are very likely, not only to guide children's attention to the relevant demonstrations, but also to suggest that the demonstration is for the purpose of instruction. Indeed, children's ability to treat the Indirect Child condition as a pedagogical condition may have been supported by the ostensive cues directed towards the other child. Additionally, note that in our studies, children were presented with a combination of verbal and non-verbal ostensive cues, whereas other studies 
(e.g. Gergely, Bekkering, \& Kiraly, 2002; Topal et al., 2008) have paired neutral language with non-verbal ostensive cues. Our manipulation was chosen to be an ecologically valid representation of the kinds of input that preschool children receive, however, further research might establish whether children would constrain their exploration if only nonverbal ostensive cues are used to indicate the pedagogical context. Finally, note that Csibra and Gergeley's claims focus on learning mechanisms present during infancy, and it is entirely possible that by the time children reach preschool, they have learned that pedagogical contexts apply beyond situations with ostensive cueing.

Our finding that children distinguish instruction to adults and other children adds to a host of studies suggesting that children are sensitive to the difference between the mental states of children and adults. Preschool children understand that adults know different things than they do (Lutz \& Keil, 2002), and indeed, children sometimes erroneously attribute omniscience to adults (e.g., Mossler, Marvin, \& Greenberg, 1976; Wimmer, Hogrefe, \& Perner, 1988). Such results are consistent with our claim that preschoolers assume that other children are learners similar to themselves but do not make this assumption about adult learners. Our studies are also consistent with a host of studies suggesting that children can learn vicariously, from overheard communication or demonstrations (Correa-Chavez and Rogoff; 2009; Jaswal \& Markman, 2003; see also Akhtar, Jipson \& Callanan, 2001; Jaswal \& Markman, 2001; Tomasello \& Barton, 1994). However, extending beyond previous work, we show that children not only learn overheard material, but also draw rational (if fallible) inferences about the absence of information that is not instructed.

Although the negative effects of instruction on exploration may seem disheartening, the results suggest a striking competence in young children: they are able to negotiate the tradeoff between exploration and instruction such that they explore more when they can rationally infer that there is more information to be learned. Moreover, children demonstrate this competence remarkably early. By preschool, children seem actively to evaluate their teachers both for the knowledge they have and their ability to demonstrate it. Thus, well before children are immersed in formal education, they are sensitive to some conditions that promote effective instruction. Furthermore, the ability to learn selectively from overheard demonstrations is presumably valuable in a world where children are surrounded by siblings and peers who are also subject to adult instruction; by interpreting pedagogical demonstrations to other children as they interpret pedagogical demonstrations to themselves, preschoolers can benefit not only from information they are taught directly but also from information provided to others.

Finally, although the current findings involve young children in a limited instructional context, the results suggest the possibility of a new perspective on longstanding debates in the field of education. In classroom contexts, advocates of discovery learning have suggested that direct instruction is passive and discourages engagement (Dean \& Kuhn, 2006; Papert, 1980), whereas advocates of direct instruction have countered that self-guided exploration is inefficient and often ineffective (Vygotsky, 1978; Kirschner, Sweller, \& Clark, 2006; Klahr \& Nigam, 2004; Mayer, 2004; Rittle-Johnson, 2006). The current results suggest that instruction leads to inductive biases that create a genuine "double-edged" sword: teaching simultaneously confers advantages for learning instructed information and disadvantages for learning untaught information. Thus, the decision about how to balance direct instruction and discovery learning depends largely on the lesson to be learned. Inspired by Piaget, the challenge for educators may be how to foster learners "capable of doing new things" while simultaneously teaching "what other generations have done". 


\section{Acknowledgments}

Thanks to Sydney Katz, Kiersten Pollard, Isabel Chang, Zhara Ghabyali, Hannah Pelton, Claire Cook, Ali Horowitz, Juan Francisco Estevez, Emily Mistretta, Stephanie Tong, Kathie Pham, the Museum of Science, Boston, and participating families. Research supported from the Elizabeth Munsterberg Koppitz Fellowship from the American Psychological Foundation (EB), the National Science Foundation (LS), the John Templeton Foundation (LS), and the James S. McDonnell Foundation (LS, EB).

\section{References}

Akhtar N, Jipson J, Callanan MA. Learning words through overhearing. Child Development. 2001; 72:416-430. [PubMed: 11333075]

Bonawitz, EB.; Lim, S.; Schulz, LE. Weighing the Evidence: Children's theories of Balance affect play. Proc 29th Annu Conf Cog Sci Soc; 2007. p. 1861-1866.

Bonawitz EB, Lombrozo T. Occam's Rattle: Children's use of simplicity and probability to constrain inference. in review.

Bonawitz EB, Schulz LE. Balancing theories and evidence in children's exploration, explanations, and learning. in review.

Bonawitz, EB.; Shafto, P.; Gweon, H.; Chang, I.; Katz, S.; Schulz, L. The Double-Edged Sword of Pedagogy: Modeling the Effect of Pedagogical Contexts on Preschoolers Exploratory Play. Proceedings of the Thirty-first Cognitive Science Society; 2009.

Bonawitz EB, Shafto P, Gweon H, Spelke E, Schulz L. The double-edged sword of pedagogy: Teaching limits children's spontaneous exploration and discovery. under review.

Bruner, J.; Jolly, A.; Sylva, K. Play-Its role in development and evolution. Basic Books Inc; New York: 1976.

Correa-Chavez M, Rogoff B. Children's attention to interactions directed at others: Guatamalan Mayan and European American patterns. Developmental Psychology. 2009; 45(3):630-641. [PubMed: 19413421]

Csibra G, Gergely G. Natural Pedagogy. Trends in Cognitive Sciences. 2009; 13(4):148-153. [PubMed: 19285912]

Dean D, Kuhn D. Direct Instruction vs. Discovery: The Long View. Science Ed. 2006; 91:384-397.

Gergely G, Bekkering H, Kiraly I. Rational imitation in preverbal infants. Nature. 2002; 15(6873):755. [PubMed: 11845198]

Gergely G, Király I, Egyed K. On pedagogy. Dev Sci. 2007; 10(1):139-146. [PubMed: 17181712]

Goodman, ND.; Baker, CL.; Tenenbaum, JB. Cause and intent: Social reasoning in causal learning. Proceedings of the 31st annual conference of the Cognitive Science Society; 2009.

Gweon, H.; Schulz, L. Stretching to learn: Ambiguous evidence and variability in preschoolers' exploratory play. Proc 30th Annu Conf Cog Sci Soc; 2008. p. 570-574.

Jaswal VK, Markman EM. Learning proper and common names in ostensive versus inferential contexts. Child Development. 2001; 72:768-786. [PubMed: 11405581]

Jaswal VK, Markman EM. The relative strengths of indirect and direct word learning. Developmental Psychology. 2003; 39(4):745-760. [PubMed: 12859127]

Kirschner PA, Sweller J, Clark RE. Why Minimal Guidance During Instruction Does Not Work: An Analysis of the Failure of Constructivist, Discovery, Problem-Based, Experiential, and InquiryBased Teaching. Educ Psychol. 2006; 41:75-86.

Klahr D, Nigam M. The equivalence of learning paths in early science instruction: Effects of direct instruction and discovery learning. Psychol Sci. 2004; 15:661-667. [PubMed: 15447636]

Koenig M, Harris PL. Preschoolers mistrust ignorant and inaccurate speakers. Child Dev. 2005; 76:1261-1277. [PubMed: 16274439]

Kushnir T, Wellman HM, Gelman SA. The role of preschoolers' social understanding in evaluating the informativeness of causal interventions. Cognition. 2008; 107(3):1084-1092. [PubMed: 18039543]

Lombrozo T. Simplicity and probability in causal explanation. Cognitive Psychology. 2007; 55:232257. [PubMed: 17097080] 
Lutz DR, Keil FC. Early understanding of the division of cognitive labor. Child Development. 2002; 73:1073-1084. [PubMed: 12146734]

Mayer RE. Should there be a three strikes rule against pure discovery learning? Am Psychol. 2004; 59:14-19. [PubMed: 14736316]

Mossler, Marvin; Greenberg. Conceptual perspective-taking in 2- to 6-year-old children. Developmental Psychology. 1976; 12:85-86.

Oaksford M, Chater N. A rational analysis of the selection task as optimal data selection. Psychological Review. 1994; 101:608-631.

Papert, J. Mindstorms: children, computers, and powerful ideas. Basic Books, Inc; New York: 1980.

Piaget, J. The Child's Conception of the World. New York: Harcort, Brace; 1929.

Rittle-Johnson B. Promoting transfer: effects of self-exploration and direct instruction. Child Dev. 2006; 77:1-15. [PubMed: 16460521]

Schulz L, Bonawitz EB. Serious fun: Preschoolers play more when evidence is confounded. Dev Psychol. 2007 Jul; 43(4):1045-1050. [PubMed: 17605535]

Shafto, P.; Goodman, ND. Teaching games: Statistical sampling assumptions for pedagogical situations. Proceedings of the 30th annual conference of the Cognitive Science Society.; 2008. p. 1632-1637.

Shafto P, Goodman ND, Griffiths TL. Rational inferences in pedagogical situations. under review.

Singer, DG.; Golinkoff, MR.; Hirsh-Pasek, K. Play = Learning: How play motivates and enhances children's cognitive and social-emotional growth. New York: Oxford University Press; 2008.

Tenenbaum, JB. PhD Thesis. MIT; Cambridge, MA: 1999. A Bayesian Framework for Concept Learning.

Tomasello M, Barton M. Learning words in nonostensive contexts. Developmental Psychology. 1994; 30:639-650.

Tomasello M, Carpenter M, Call J, Behne T, Moll H. Understanding and sharing intentions: The origins of cultural cognition. Behavioral and Brain Sciences. 2005; 28:675-735. [PubMed: 16262930]

Topal J, Gergely G, Mikolsi A, Erdohegyi A, Csibra G. Infant perseverative errors and induced by pragmatic misinterpretation. Science. 2008; 321:1831-1834. [PubMed: 18818358]

Wimmer H, Hogrefe J, Perner J. Children's understanding of informational access as a source of knowledge. Child Development. 1988; 59:386-396.

Vygotsky, L. Mind in Society. Cambridge, MA: Harvard University Press; 1978. 


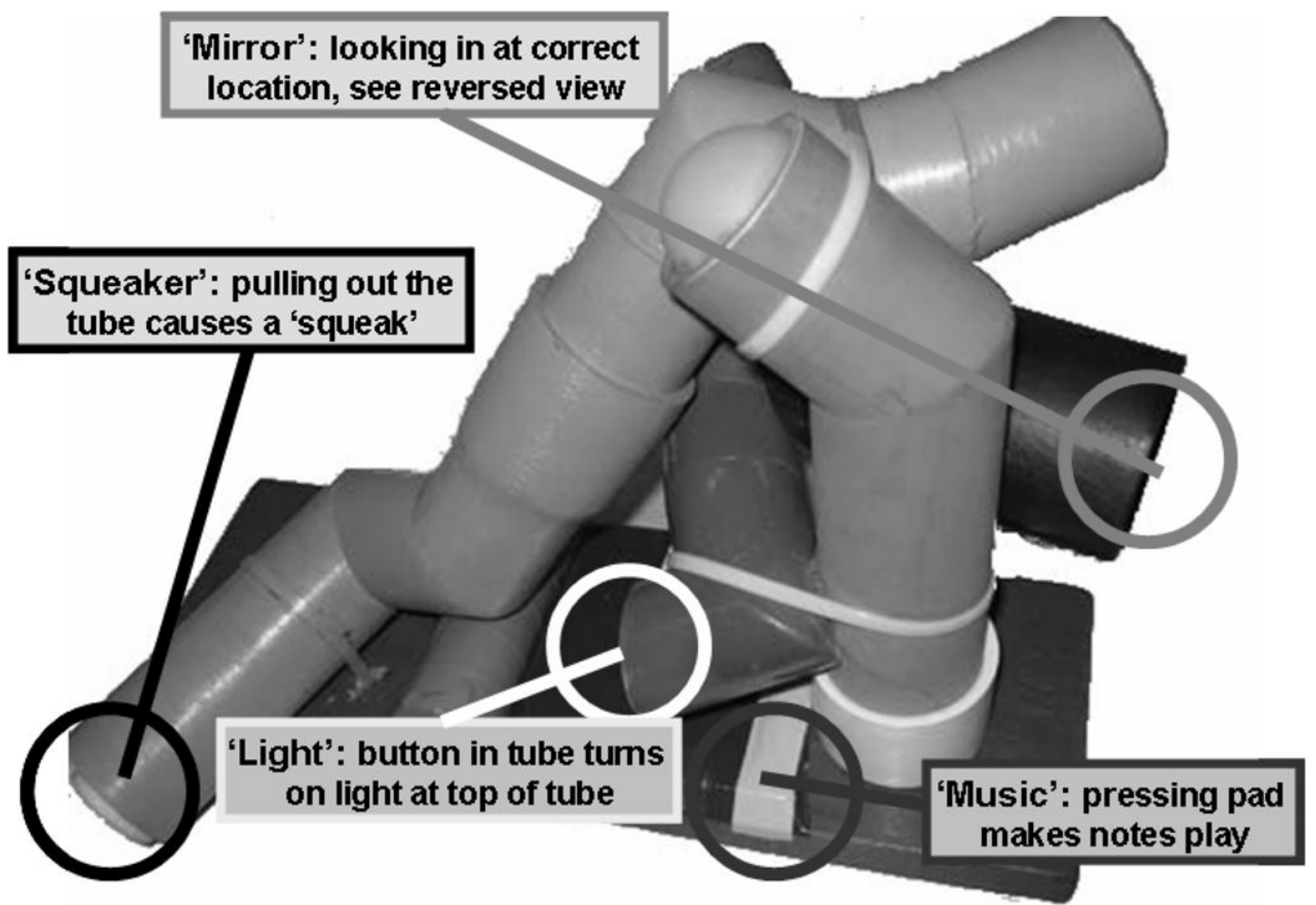

Figure 1.

Novel toy stimuli used in experiments 1 and 2. 